\title{
Innovation and beyond
}

\author{
JH Nantel Nantar Engineering Ltd., Canada
}

\begin{abstract}
Does a low level of innovation condemn the mining industry to mediocrity or failure?

What lessons can the mining industry draw from other industrial sectors? In the high tech world, failure to innovate is the kiss of death. How did Blackberry manage to blow its runaway lead and become a minor player in the smartphone market it invented? Can the same destiny be lurking for mining corporations that fail to innovate?

Mine backfill represents a core area where innovation could benefit the entire mining operation. The filling process controls how fast and how well a mine operates.

The mining industry is beginning to show a renewed interest in mine research. Is this more talk than action? Some will point out that the mining industry never recovered from the research and development (R\&D) slowdown that followed the productive period of the 1980s and 1990s.

The author will explore the parallels between industries and outline a blueprint for what the mining companies need to do to stay competitive. The model proposed will require the leaders of the large mining companies to take charge of innovation. The model is simple: big companies, big ideas and big contributions.
\end{abstract}

The mining industry must continue to innovate to remain viable.

\section{$1 \quad$ Introduction}

Thank you Mr Chairman, I'm very pleased to be here. And to paraphrase George Burns "At my age, I'm pleased to be anywhere" (Burns 2012).

Mining is a very old profession. It is a toss-up between mining and prostitution as to which one is the oldest. When one does an internet search with the word's 'oldest profession', mining does not automatically come up at the top of the list, prostitution comes out on top. You have to drill down a bit before you arrive at mining. Some say that mining and prostitution go well together. After all how hard would it be to get ladies of easy virtues with men with low scruples together? So it was tempting to combine both professions and write a paper on this, but I found out that someone had beaten me to it with a paper entitled 'Prostitution in the Mining Camps' (Adams 1997). Consequently I'll restrict my presentation to what I know best: mining.

Is it possible to cut your operating costs by $10 \%$ just by attending this 11 th International Symposium on Mining with Backfill (Mine Fill 2014)? You will be able to do that if you follow all the presentations carefully over the next three days, then go back to work after the symposium and apply what you have learned. It is that simple. Now if you attended Dr Cooke's Best Practices in Mine Backfill Technologies Workshop, then you can save another $10 \%$ on your operating costs.

I will further add that in order to be able to cut your costs by $10 \%$ it does not necessarily require the use of new technologies; in most cases all you need to do is to apply tried and tested technologies in a competent manner. There is a bit of irony here: some technologies may appear novel, but most have been around for a number of years. All you have to do is to discover them and use them in your operations. We, of course, should always be on the lookout for better ways to do things. All of us gathered here at this Mine Fill 2014 Symposium can do much to change the prevailing form of mining by applying the latest proven technologies and equipment, and by working on new ones. 
The only way to improve the status of mining is to work diligently on it. Good things will happen if we apply a very robust regimen of research in the industry. The slowdown in mining research efforts that occurred in the mid 1990s did not help the mining industry.

\section{$2 \quad$ The case for mine backfill}

As this is a symposium on mining with backfill, let me establish right at the beginning the full importance of backfill in mining: one cannot mine any faster than one can fill.

Arguably the heart of the mining operation is the stoping method and all the other facilities that are an essential part of what makes a safe and efficient mining operation. The mining and removal of the ore is intricately meshed with the facilities required to hoist, to ventilate, to handle supplies, to communicate, to move workers and materials, etc., and of course, to backfill.

It is not a stretch to say that a mine could be designed around the backfill system, not the other way around. The mine design approach could go like this:

- The best possible mine fill will dictate the selection of the mining method and adapt it to all the other physical attributes of an orebody.

- Then the mining method will dictate the type and size of mining equipment, the mining strategies, the sequences, etc.

- In turn the equipment will dictate the size of material produced, the size of mine openings, ore passes, shafts, ramps, etc.

- This approach will produce a smooth and predictable ore supply at grades within acceptable limits conducive to enhanced mill efficiencies.

It is well documented that improved mine fill opened the way to new extraction methods. A few examples: the use of cemented fill gave rise to improved cut-and-fill methods, and the advent of paste fill gave rise to better large stope sequencing and faster production cycles.

Another positive aspect of centring the design of mines on backfill is to fill all voids created by mining: stopes, developments, etc., before the mine is wound-up, resulting in essentially zero tailings on the surface and thus reducing greatly the footprint of mining. This consideration is not insignificant.

Without getting into all the factors affecting mine design, it is fair to say that a better interrelationship between all the various mining components results in higher financial returns for a given orebody.

The Australian Centre for Geomechanics (ACG) 'Handbook on Mine Fill' (Potvin, Thomas \& Fourie 2005) also advocates the use of mine fill as the centrepiece of a holistic mine design. The ultimate goal has to be how to mine at the utmost efficiency. A great deal of this will come from a good understanding of all processes and bringing them back to their basic simplicity. Just like the Theory of Everything in Physics: not 15 different laws, just one that explains and simplifies everything.

I should point out that as we speak, the Theory of Everything has not been formulated yet; we need to reconcile the Theory of General Relativity and Quantum Mechanics, they (I was going to say we) are still working on it. If a solution is in hand by the next Mining with Backfill symposium, l'll report on it. The same goes for mining: we have not simplified everything to one formula yet.

A new paradigm for mining could very well be the one espoused by Apple in their latest video on launching the iOS 7 operating system, "bring order to complexity through simplicity" (Apple Inc. 2013).

\section{$3 \quad$ Historical perspective of innovation in mining}

When I started in mining research at Noranda in 1982, a good number of people were asking me: is there anything to research in mining? And they would proceed to answer their question: you break the rock, load it into trucks or cars, and bring it to the mill. What else do you want to know? What is there to research? 
Many did not see what could possibly be improved upon, just like if the car could not be improved upon after Henry Ford or Karl Benz built their first cars, or that nothing could be improved upon after Steve Jobs invented the first personal computer.

I said at the time that just about anything we do in mining needs to be improved, changed, or rendered obsolete. 32 years later, I still hold the same belief. In fact, it will need to be said for a long time to come, because we will never get there. Tiger Woods said, "Your game never gets perfect, you have to keep improving all the time" (Woods 2010). There is nothing in our business that cannot be re-invented or dramatically improved upon and that includes mine backfill.

Someone has to develop innovative stuff. Someone has to be first, we cannot all be the 'first to be second'. Here is an example of someone who wants to be first to be second as read on Linkedln:
"Can you direct me to operations which are current users of Gadget 570? Please send complete information and pricing for this product to (...)@myemailaddress.ca. We are currently in the testing stages of our definitive feasibility study and would like to take a look at the merits of this alternative product" (Linkedln 2013).

Sound familiar? We have all done it. With this approach we would all be 'seconds' and tread the paths that someone had beaten for us. There is nothing fundamentally wrong with this approach, but at a certain point we need to innovate - to come up with something new, something more efficient.

Shortly after my arrival at Noranda we conducted a survey and we discovered that the research work we were doing was paying off for Noranda. An evaluation group took 60 research and development projects and estimated that the benefits from those projects were approximately triple the costs of the research. It is worth noting that amongst the 60 projects chosen for this survey, several were failures (Wolff 1985).

Other studies show that most research projects fail. One should not be discouraged by this. In order to succeed, one has to fail. Someone said "Nothing succeeds like failure" (Schiff 2013).

The mining industry had a golden era of mining innovations from the early 1980s to the mid 1990s. Several large and small mining companies were on-board with the goal to reinvent mining as we knew it.

This resulted in dramatic innovations, including:

- Better drills, changing to hydraulic from pneumatic.

- The introduction of more sophisticated cable bolts and the theories supporting their applications.

- Improvements in backfill: better understanding of fill materials and behaviour, cement addition, and paste fill. In large part, this series of International Symposia on Mining with Backfill started in 1973 by $\mathrm{Dr}$ Ed Thomas had a great deal to do with better fill materials and practices.

- Technology that allows bigger equipment and more productivity for open pit mine operators: trucks with over 200 sensors, 750 t gross weight, $400 \mathrm{t}$ of payload travelling at $70 \mathrm{kph}$. Similar improvements for shovel, loaders, drills, etc., and all of these communicating in real-time.

- Large diameter blasthole drills for underground applications.

- Computerised mine modelling, mine design and mine monitoring for both underground and open pits.

- More sophisticated geomechanics concepts: better understanding of principles, constitutive laws and applications to mining.

- Introduction of remote control and the automation of mining equipment.

- Great efforts to develop continuous machines for hard rock formations, analogous to potash and coal mining machines, using electric blasting and disc cutters. 
Some mining industry participants will recall the great days of mining research in the early 1980s. In Canada, for example, many company CEOs were the champions of mining research. Then things slowed down very significantly, with several major mining companies closing their research departments.

In my opinion, we have never fully recovered from this R\&D slowdown. The mining industry is indicating a renewed interest in mine research. Is this more talk than action? Time shall tell.

The good work done here at the Australian Centre for Geomechanics is to be applauded and is an example to the rest of the mining world. Australia presently spends over three times as much as Canada on mining research. Have all the acquisitions and reorganisations in the mining sector in Canada been contributing to this situation? I say probably, even if I do not have any documented data to prove it. But perusing through the websites of several major acquiring companies and trying to find research work being done at present, is somewhat disappointing.

These findings support the views expressed by The Canadian Chamber of Commerce (2013) in its recent report: 'Mining Capital: How Canada Transformed Its Resources Endowment into a Global Competitive Advantage'. Although the title is glowing, the report casts a dimmer view of the mining R\&D in Canada. In it we can read:

"Mining firms still support their own research facilities, but this approach is increasingly rare for a number of reasons. Developing new mining technologies and practices are typically extremely capital intensive, requiring input of anywhere from several hundred millions to a few billion dollars. However, the payoff from these investments is very uncertain and represents an added risk for an industry already facing fluctuating commodity prices. With so much at stake, large investments in innovation often are not economical for individual firms" (The Canadian Chamber of Commerce 2013).

The author will echo this statement based on his experience at Noranda. I have overseen over CAD $150 \mathrm{~m}$ of research and development while at Noranda to develop a continuous mining machine based on plasma blasting (CAD $30 \mathrm{~m}$ by Noranda, Figure 1), a continuous mining machine based on disc cutters on articulated arms (CAD $50 \mathrm{~m}$ in association with Inco and Falconbridge, HDRK Mining Research Ltd., Figure 2), modifications made to Voest-Alpine and Dosco road headers to tackle hard rock formations (CAD $10 \mathrm{~m}$ Figure 3 ), remote control and automation of mining equipment (CAD $10 \mathrm{~m}$ ), computerised mine modelling, mine design and mine monitoring for both underground and open pit, sophisticated geomechanics research for better understanding of principles and applications to mining, etc. (20-30 m). Dr Yves Potvin was there with me throughout.

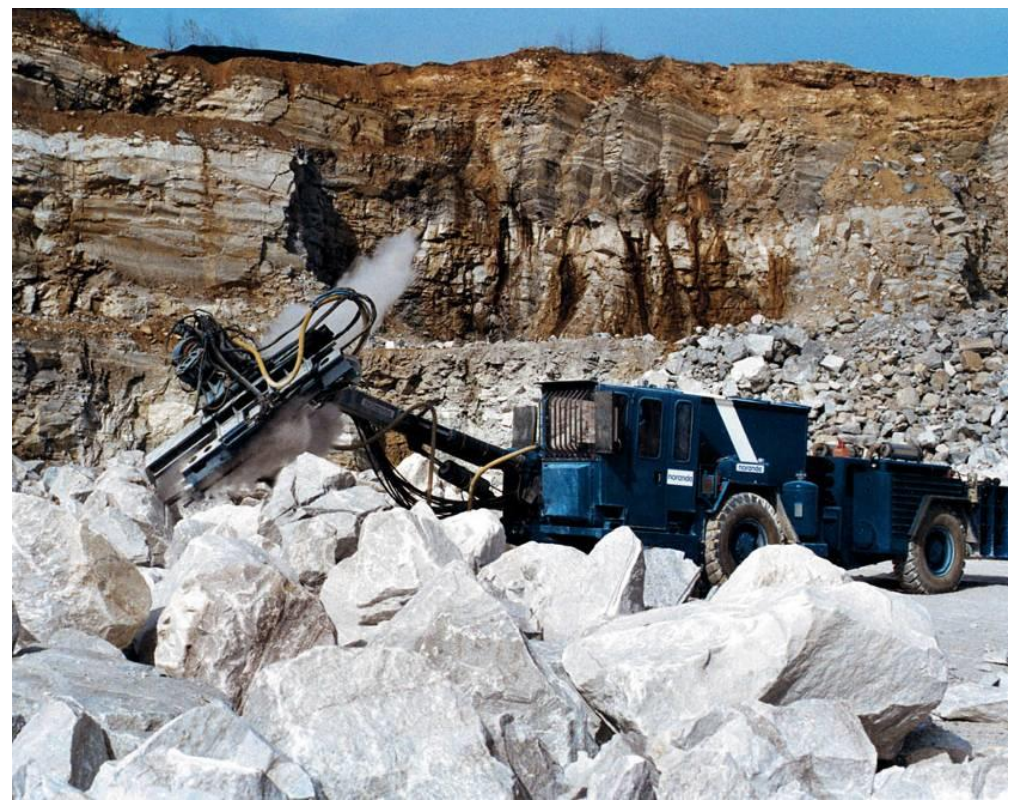

Figure 1 Plasma blasting machine developed by Noranda 


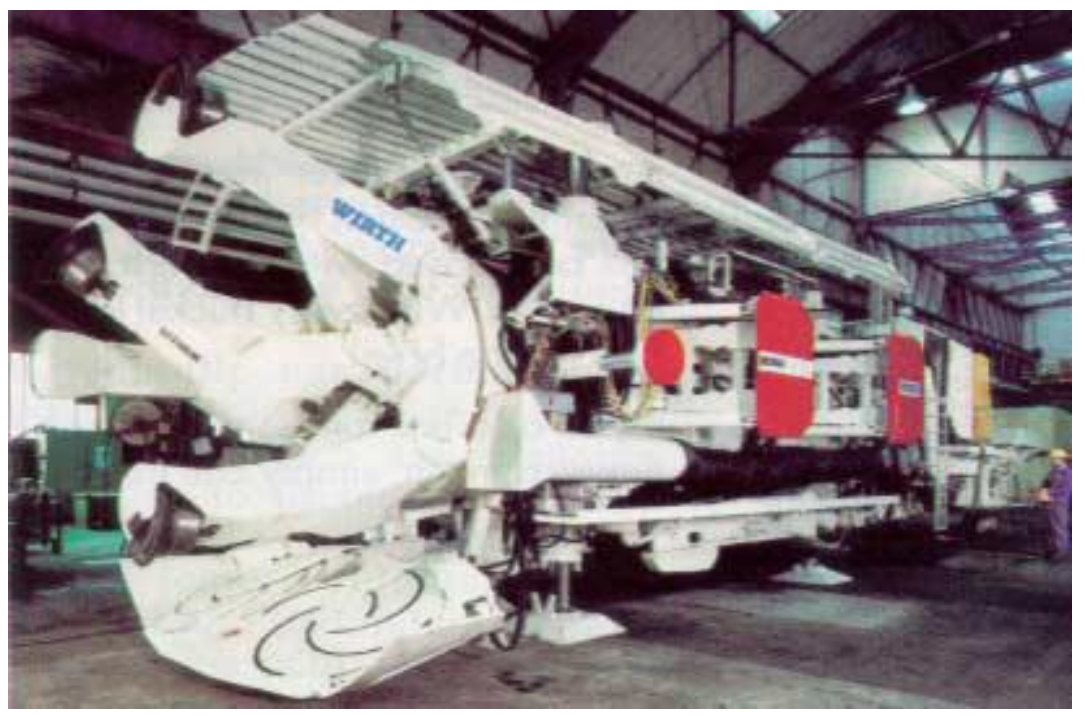

Figure 2 Continuous mining machine based on articulated arms and disc cutters (developed by the HDRK Consortium)

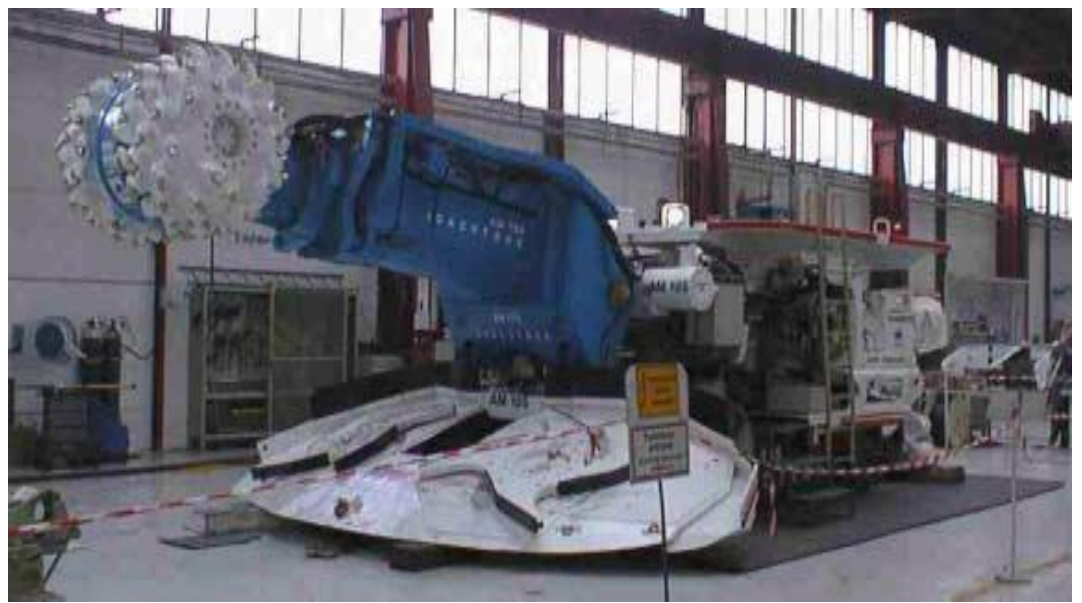

\section{Figure 3 Modified Dosco road header for HDRK}

With the mining industry entering a period of slowdown, it might be difficult to rekindle the research efforts. But we must.

Pakalnis summarised the status of mining research in Canada. At the moment it looks like this:

- Canadian mining companies: 58 metal and 1,040 non-metal mines.

- Three national research brokers: Canada Mining Innovation Council, Centre for Excellence in Mining Innovation, and the Canadian Mining Industry Research Organization.

- Federal and provincial government funding agencies and several mining research organisations: MIRARCO (Ontario), COREM (Quebec), C-CORE (Newfoundland), CANMET Materials Technology Laboratory (Federal Government), International Minerals Innovation Institute (Saskatchewan) and the following universities: Laurentian University, Queen's University, McGill University, University of Toronto, Dalhousie University, Université Laval, University of Alberta, The University of British Columbia and Ecole Polytechnique (Pakalnis 2013a).

As Vic Pakalnis puts it, 'Canadian mining research is at a very fragile level' (Pakalnis 2013b).

Vic Pakalnis goes on to say in an essay published in the CIM Magazine in October 2013 titled 'Canada Needs to Rediscover its Innovation Streak', that Canada is still doing poorly in innovation, particularly in mining 
(Pakalnis 2013b). He recommends that the examples of the Canadian automotive and forestry sectors be emulated to bring some vigour back to R\&D in mining. He goes as far as suggesting that Canada should adopt the Australian model of levying a fee for every tonne of commodity mined.

Other mining industry representatives are of the opinion that we need to do a better job going forward. Mark Cutifani, Head of Anglo American said so in a keynote address at the World Mining Congress in Montreal in August 2013 (Cutifani 2013). He bemoaned the short-term view of mine operators. He acknowledged that the industry is underspending on innovation and observed that the mining industry spends $80 \%$ less on technology research and innovation than the petroleum sector.

Peter Munk said the following about finding and operating new mines:

"There is a new world out there and woe to those in the mining industry who do not recognize that. The possibility of finding large mines today without major competition from big competitors is gone. So unless you can play in that league, vacate the field" (Munk 2013).

Similar things can be said today about those who are not prepared to innovate. As the field enters the 'major league' there will be no room for minor league players.

\section{$4 \quad$ Failure to innovate}

\subsection{How does it apply to mining, or does it apply at all?}

What are the consequences of failing to innovate in mining and failing to innovate in mine fill in particular?

As I was preparing for this address, I was struck by the demise of Blackberry in Canada. An article in the Globe and Mail, 29 September 2013, puts it this way:

"Investors, who have lived through the destruction of more than \$75-billion of the company's market value over the past five years, are still wondering how BlackBerry managed to blow its runaway lead and became a bit player in the smartphone market it invented" (Silcoff et al. 2013).

To put this in perspective, CAD $75 \mathrm{~b}$ is more than the market value of large companies like Anglo American, Barrick, Freeport-McMoRan Copper \& Gold, Caterpillar Underground Mining, Newmont or Teck. Can anything like this happen to any company big or small in the mining sector that fails to do what is right as we so often hear. Can a mining company meet its demise because it fails to innovate or adapt to changing demands? Can this happen to BHP Billiton, Vale, Rio Tinto, Anglo American, Suncor Energy Inc, Glencore Xstrata or Barrick?

There are similarities between high tech and mining companies but there are also important differences.

Let's take a look at mining. On the positive side, mining has been around for long time, one of the oldest professions, and mankind will continue to use metals for a long time to come. One could say that mining has a long past and that mining will be around long into the future. Miners like to say that mining is the future.

In high tech businesses, companies are coming up with new products all the time, like the Blackberry. In high tech businesses, things do not last forever and change quickly. In this type of business the products of today are doomed to obsolescence and, more often than not, protecting your current products is a recipe for disaster.

Kodak is an example of a company that invented digital photography. But they put it aside to avoid interfering with their profitable film business. Later, other companies adopted digital cameras and forced Kodak into bankruptcy.

In some other businesses the products last longer like Coke, soap, tobacco, food, etc., and the surviving strategies will vary and the approach to innovation needs to be adapted to the type of business. 
In the mining business the products are commodities like gold, copper, uranium, etc. They last essentially forever and are likely to be used for the foreseeable future in spite of substitutions like ceramics, plastics, fibre optics, composites and others. Ernst Young has compiled a long list of threats the mining world is facing with substitution and the mining world should pay attention (Ernst Young 2013).

But for mining companies, the 'product' is always the same, and can be produced by another company. The question, 'how we can mine better?', is what differentiates one operator from another. For a mining company, it is finding methods that will result in lower unit costs, higher productivity, greater safety and sound environmental practices. This in turn will permit a company to mine lower grade orebodies, to extract more metals from a site, to generate added value from each mine, to add years of life to an operation, to become financially stronger and to boost the economy of the countries in which they operate.

In other words, in mining, success does not rest solely in protecting the products.

Finding new applications for a metal could also mean added business to a company, as demonstrated by Inco when they literally created a market for nickel. Without this effort by Inco scientists, several daily products we use today would not exist and several deposits would never have been mined. This created big business opportunities for Inco. When I was at Noranda, we had several research projects devoted to find new properties for zinc and other commodities that could lead to increased usage in a variety of industries and consequently a higher demand for Noranda's products.

A bit of irony here, someone may ask, what happened to Inco and Noranda? All I can say is that they are still around but operating under different names.

\subsection{What are the incentives for mining companies to do research?}

I affirm that the incentive to conduct research or to pursue innovations is not as imperative for mining companies as it is for high tech companies. As mentioned, in the high tech world, if you do not conduct research to replenish your products you will cease to exist. But in the mining world, if you do not conduct research you will not necessarily go out of business.

This is likely one of the reasons why the mining industry is in the minor leagues when it comes to innovation. Let me put it using a sports analogy, the NHL for the Canadians, the NFL for the Americans or the AFL for the Australians does not exist in the mining world of research and innovation.

In the mining world, a company is more likely to go out of business because it is taken over by another company with greater financial acumen and more inclined to risk-taking. But even in this case, the mine or operation may not go out of business, but will be operated by someone else. The orebody will be mined, but not by you. Several examples of this exist in Canada.

\section{$5 \quad$ A new research model is required}

If the mining industry wants to get out of the minor leagues, a new research model is required. Collaboration seems to be the one favoured by mining actors. The mining industry could use a whole new structure, more coherent, across the entire system.

We all appear to be in agreement that innovation is generally accepted as the means to create a sustainable competitive advantage for organisations. Innovation is also accepted as a driver of economic growth. That is the theory or the prevalent thinking in essentially all sectors of economic activities. Mining companies are aware of the needs and benefits of R\&D and the producers with the best technologies will have an advantage. Now let's do it.

The model proposed here will require the mining leaders of the big mining companies to take charge of innovation. The big companies have a duty and an obligation to come up with big ideas and big contributions to transform the mining industry.

Mr Cutifani, quoted previously, is right to assert that the mining industry is underfunded in the R\&D department. Let's put our companies' talent and money where we want them to go. It is grand time for 
mining companies to start operating mines efficiently like several other industries do, such as manufacturing plants, just-in-time factories and Amazon.com.

My research model is simple: big companies, big ideas and big contributions.

The amounts to be invested are likely to be in the hundreds of millions for the invention and development of novel equipment or processes.

This simple model can be applied along the following streamlined diagram.

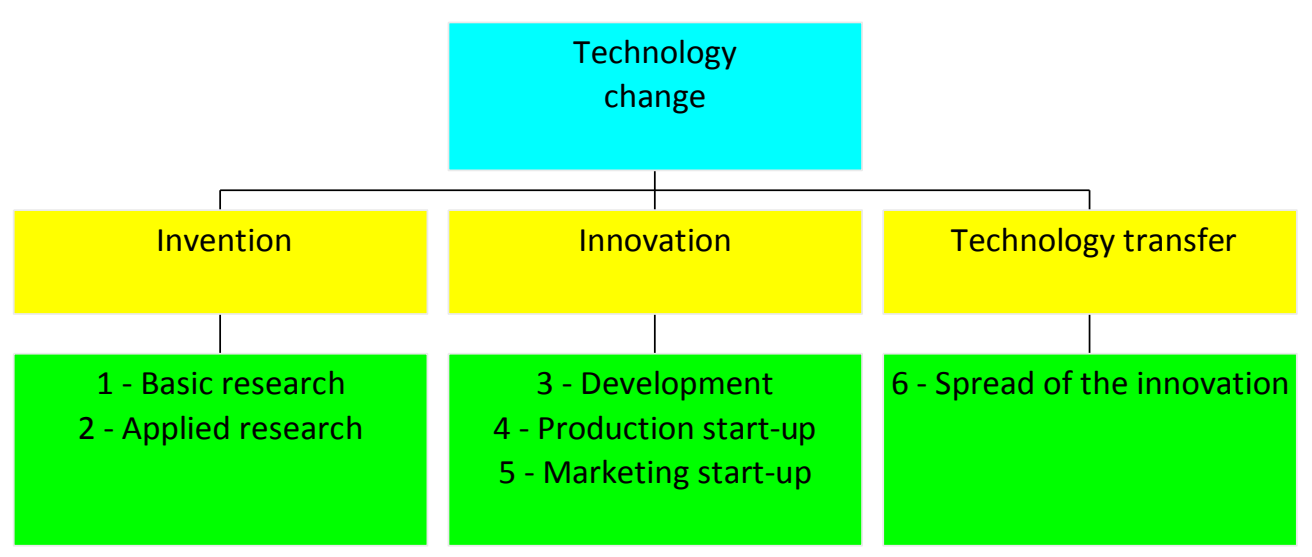

Figure 4 Simplified R\&D model for the mining industry

\subsection{The next 50 years}

As the 'good' orebodies or the low hanging fruit are slowly disappearing, we will be forced to start mining resources of lower grades, at greater depths and in more challenging environments. The present methods will not cut it. Only dramatically novel technologies will permit us to mine what are now considered mineral resources. Mining waste and sub-marginal material cannot be called mining, recovery, conservation or optimisation of resources if a company is losing money doing it. But if we can come up with efficient methods to mine these low grade deposits at a profit, this indeed can be called mining and is a way to optimise commodity recoveries and conservation. We do not have to look very far in the natural resources world to see how that can be achieved: the oil and gas businesses are already doing it. They have perfected hydraulic fracturing or 'fracking' and now can extract from countless oil and gas fields once considered depleted. Remember that they spend five times more that the mining industry on innovation.

The mining industry needs its own version of 'fracking' for the next generation of orebodies.

How will the mining industry get to the next game changer? Are its seeds to be found here at this symposium? What would be the equivalent of 'fracking' in mining?

Let me discuss a few areas that could revolutionise the mining industry.

\subsubsection{Mine fill distribution, instrumentation and data gathering}

We cannot claim to know what we are doing if we do not have strong data. While mine backfill plants are becoming more automated and instrumented, especially with paste fill operations, underground backfill distribution systems are slow to change. Fill properties are appropriately measured in the preparation plants but as backfill enters the mine borehole, the technology for control, data gathering and reporting is somewhat lacking.

Many mines are experiencing problems with borehole and pipeline plugging, pipeline bursting, bulkhead failure and exposed fill sloughing. With adequate instrumentation of the backfill system it may be possible to obtain a complete, continuous and detailed picture of the entire filling operation from preparation to post-pour. Monitoring directly relates to mine safety and productivity by forecasting problems, preventing 
dilution of ore and by providing early warning of instability, which will permit timely action and prevent costly delays or shutdown associated with fill or backfill system failures.

With the advent of rugged and powerful computer capabilities, data gathering and analysis, this task should not prove insurmountable. Good data will, over time, provide the basis for needed improvements of backfill systems and will be essential to safer, more efficient and less costly fill practices. It is imperative that mining operations embark into the development of computerised backfill databases. Some companies (Bulldog Ventures 2013) now offer onsite computing facilities to mining companies capable of handling vast quantities of data in extreme conditions.

Computer data gathering systems would incorporate search routines to arrange and summarise information based on location, date, type of observations or a combination of parameters. All types of files could be incorporated into the system: photos, drawings, engineering standards for bulkhead design, etc. The program should be tailor-made for specific mines with the possibility to generate all the reports and output required by the operators. These can include, for example, forms given to the workers, mine foremen, engineers, management, governments, etc.

\subsubsection{Continuous mining machines for hard rock formations}

A great number of practical minds in the mining industry agree that productivity leaps will come only from our ability to mine hard rock formations in a continuous manner just like we do in potash, salt, and coal, where productivity is several times those achieved in hard rock mines. The continuous machines used in the potash mines of Saskatchewan are 'chewing' potash at a rate of 2,000 t/h.

With continuous mining, the mining infrastructure can be turned on its head: ground pre-conditioning, better engineered ground support, smoother and more predictable flow of material. A mining operation would look completely different if the mine design was based on a continuous mining machine. For example, all voids could be filled shortly after mining. In situ ore sorting could be part of such a system, where mine waste would not need to be hauled to surface. All functions would be monitored and controlled: the ground, the machines, all aspects of anything that moves at a mine site and fed into dynamic simulations. This of course would generate a gigantic amount of data. The mining industry could become a leader in this area as well, replacing the National Security Agency (NSA) in the USA. We would be getting closer to a factory than a mine.

It is still a matter of conjecture as to what will form the basis of continuous mining machines. Will it be a machine based on brute force similar to tunnel or raise boring machines equipped with drill bits or cutters made of ultra-hard materials? Will it be a hybrid machine based on cutters, high pressure water jets, electrical or hydraulic blasting, neutron bombardments, etc.?

I place my bets on machines based on a new generation of ultra-hard materials.

When tungsten carbide came on the mining scene around 1930, the use of cemented carbide tips increased the lifetime of drill bits by a factor of ten compared to steel-based drilling tools. The same revolution had occurred in the steel industry only a few years before. The hard metals have been perfected since, but they are essentially the same as they were 80 years ago.

It is worth noting that it is not against the laws of physics to have materials harder than diamond. A case in point: researchers at Rice University, Texas, USA (Williams 2013) have assembled a form of carbon named carbyne, an elusive allotrope of carbon, that could be as much as three times harder than diamond. Diamond has a hardness of 7,000 on the Knoop hardness scale and tungsten carbide comes in at 2,000.

Today, at this Mine Fill 2014 Symposium, I proposed that the mining industry embark on one of the most ambitious research project to date: the development of the next generation of ultra-hard materials.

This project will create ultra-hard materials to replace existing products with a hardness of 5-10 times that of tungsten carbide and with a better resistance to impact. The hardness would surpass diamond in order to reach hardness ratios of over 50 , i.e. the drilling or cutting material is 50 times harder than the substance 
being drilled or cut. At present, with tungsten carbide products the ratio is barely three in some hard rock formations.

This type of research can be described as radical and would revolutionise the mining industry. Some may call it a game changer. This research would render existing hard materials obsolete. Developments of this sort have been rare in the mining industry in the last 80 years: the invention of dynamite, the advent of tungsten carbide products to replace hard steel products. The oil industry would also benefit greatly from the use of drill bits made from super hard materials.

The mining industry should be at the forefront of this research in partnership with the oil industry. This research effort is likely to cost over CAD $1 \mathrm{~b}$ over ten years. It will require contributions by the biggest names in the mining and oil industry: BHP Billiton, Glencore Xstrata, Vale, Rio Tinto, Shenhua, Anglo American, Suncor Energy Inc., Teck Resources Ltd, Barrick, General Electric, Exxon Mobil Corporation, Shell, Chevron Corporation, BP p.I.c., Total SA, Caterpillar Inc., just to name a few (Forbes 2013).

Such a project will bring together the most powerful mining houses in the world and the finest brains in the research world to work together to conquer one of the toughest challenges in mining so far. On the research side, all the big research institutions in physics, metallurgy, mining will be called to task: Rice University, Lawrence Livermore, ACG, CSIRO, etc.

How is such a project linked to mine fill, you may ask? Continuous mining machines will require continuous filling and new backfilling materials and techniques will have to be invented.

\subsubsection{In situ mining}

Another approach that could turn mining on its head is in situ mining made possible by hydraulic fracturing. In situ leaching of orebodies is already done for some commodities like copper, gold and uranium. $45 \%$ of the global uranium production in 2012 was achieved through some form of leaching (Diniz 2013).

Could that represent mining of the future for several other metals? The advantages are obvious: no need to send any miners underground and sadly to say, no need for fill. The oil sands is perfecting a form of in situ mining called steam assisted gravity drainage (SAGD), where pairs of horizontal boreholes are drilled into the oil formation and high pressure steam is injected into the upper borehole to heat the oil and reduce its viscosity causing the oil to flow into the lower borehole (Cenovus Energy Inc. 2013).

Could directional drilling coupled with hydraulic fracturing and new types of leaching agents to dissolve the targeted metals be used in the future?

Can fracking accomplish for mining what it has done for the oil and gas industries? To quote a BBC news report on 23 June 2013:

"Fracking allows drilling firms to access difficult-to-reach resources of oil and gas. In the US it has significantly boosted domestic oil production and driven down gas prices. It is estimated to have offered gas security to the US and Canada for about 100 years, and has presented an opportunity to generate electricity at half the $\mathrm{CO}_{2}$ emissions of coal" (BBC News 2013).

Why move millions of tonnes of waste when we could just go and get what we want, remotely! Is this where we want to go, and if so, how do we get there? This would create a need to develop better leaching products for all sorts of metals that are also intrinsically environmentally safe.

The mining industry needs its own version of fracking for the next generation of orebodies. We may have only a few more decades for this to be the case in mining.

One caveat, however, given the current level of controversy associated with hydraulic fracturing around the world, this approach may face a steep uphill battle. 


\section{$6 \quad$ Concluding remarks}

One thing is clear, the mining industry cannot stand idle while the rest of the world keeps innovating and changing. We need to revive and maintain a culture of innovation and this will be done from the top down and the bottom up in all sectors of the resources world. We need to bring new blood into the industry. The miners have to associate with people other than other miners.

With the mining industry entering a period of slowdown, it might be difficult to rekindle the research efforts. But we must.

We need to keep improving productivity through adequate training of employees, to develop a positive attitude toward new technology and to augment productivity with new machines.

Someone in attendance today will come and deliver the keynote address at the 2064 International Symposium on Mining with Backfill. What will he/she say? (Sorry Ed Thomas, it won't be you nor I).

On this, Mr Chairman, I would like to conclude with the following, "Someone told me one day that the secret of a good speech is to have a good beginning and a good ending, then having the two as close together as possible."

I hope you did not find the middle too long.

Thank you.

\section{Acknowledgement}

I thank the Organising Committee for the opportunity to present this keynote address and acknowledge the assistance of Jim Tod of Golder Associates Ltd., Canada in producing this paper.

\section{References}

Adams, K 1997, Angels or Whores: Prostitutes in the Mining Camps, viewed 17 December 2013, http://www.3rd1000.com/history3/ events/aorw.htm

Apple Inc. 2013, iOS7 The mobile OS from a whole new perspective, Apple Inc., Cupertino, viewed 17 December 2013, http://www.apple.com/ios

BBC 2013, What is fracking and why is it controversial?, BBC, viewed 17 December 2013, http://www.bbc.co.uk/news/uk-14432401

Bulldog Ventures 2013, The Bulldog Mobile Data Center, Bulldog Ventures Ltd., Abbotsford, viewed 17 December 2013, http://www.bulldogcontainers.com.

Burns, G 2012, Laughter is Medicine, SevenPonds, San Francisco, viewed 18 November 2013, http://blog.sevenponds.com /laughter-is-medicine/im-very-pleased-to-be-here-lets-face-it-at-my-age-im-very-pleased-to-be-anywhere.

Cenovus Energy Inc. 2013, Steam-assisted gravity drainage (SAGD), Cenovus Energy Inc., Calgary, viewed 17 December 2013 , http://www.cenovus.com/operations/technology/sagd.html

Cutifani, M 2013, 'Cutifani pitches long-term view in his keynote address at the 23rd World Mining Congress 2013', CIM Magazine, September 2013.

Diniz, V 2013, Uranium and the United States: Colin Healey, Uranium Investing News, Vancouver, viewed 17 December 2013, http://uraniuminvestingnews.com/15801/uranium-and-the-united-states-colin-healey.html.

Ernst Young 2013, The super-cycle hangover: the rising threat of substitution, Ernst \& Young Global Limited, viewed 17 December 2013, http://www.ey.com/Publication/vwLUAssets/The_rising_threat_of_substitution_-_mining_and_metals /\$FILE/ey-threat-of-substitution-sep2013.pdf

Forbes 2013, The world's Biggest Public companies, Forbes.com LLC, New York, viewed 17 December 2013, http://www.forbes.com /global2000/list/\#page:1_sort:6_direction:desc_search:_filter:All\%20industries_filter:All\%20countries_filter:All\%20states

LinkedIn 2013, November 2013 Discussions blog, LinkedIn, Mountain View, viewed November 2013, http://www.linkedin.com.

Munk, P, 'Peter Munk's extraordinary career of booms and busts', The Globe and Mail, viewed 8 November 2013, http://www.theglobeandmail.com/report-on-business/peter-munks-extraordinary-career-of-booms-andbusts/article15360801

Pakalnis, V 2013a, 'Wither Canadian mining research', Canadian Government Executive, vol. 19, no. 7, p. 30.

Pakalnis, V 2013b, 'Canada needs to rediscover its innovation streak', CIM Magazine, vol. 8, no. 7, p. 36.

Potvin, Y, Thomas, E \& Fourie A 2005, Handbook on Mine Fill, Australian Centre for Geomechanics, Perth.

Schiff, L 2013, Business Brilliant: Surprising Lessons from the Greatest Self-Made Business Icons, HarperBusiness, New York, NY.

Silcoff, S, Mcnish, J \& Ladurantaye, S 2013, 'Inside the fall of BlackBerry: How the smartphone inventor failed to adapt', The Globe and Mail, viewed 29 September 2013, http://www.theglobeandmail.com/report-on-business/the-inside-story-of-whyblackberry-is-failing/article14563602/ 
The Canadian Chamber of Commerce 2013, Mining Capital: How Canada has Transformed its Resource Endowment into a Global Competitive Advantage, The Canadian Chamber of Commerce, Ottawa, p. 35.

Williams, M \& Falk, J 2013, Carbon's New Champion, Rice University News \& Media, viewed 24 February 2013, http://news.rice.edu /2013/10/09/carbons-new-champion/

Wolff, MF 1985 'How is the R\&D Lab Doing? NORANDA Finds Out', Research Management, vol. 28, no. 4, July-August 1985, pp. 9-10.

Woods, T 2010, Television interview 2010. 